\title{
Reseña de Maestro, Jesús G., Calipso eclipsada. El teatro de Cervantes más allá del Siglo de Oro, Madrid, Editorial Verbum, 2013, 316 pp. (ISBN: 978-84-7962-899-4)
}

\author{
Víctor Miguel Gutiérrez Pérez \\ Tecnológico de Monterrey \\ MÉXICO \\ vm.gutierrez.phd.mty@itesm.mx
}

[Hipogrifo, (issn: 2328-1308), 2.2, 2014, pp. 179-183]

Recibido: 23-05-2014 / Aceptado: 26-05-2014

DOI: http://dx.doi.org/10.13035/H.2014.02.02.13

Este libro, que en su poética presentación se ofrece al lector como la segunda entrega de una trilogía iniciada con La escena imaginaria. Poética del teatro de Miguel de Cervantes (2000) y que, como dice el propio autor, Fortuna mediante se espera concluir con El triunfo de la heterodoxia. El teatro de Cervantes en la literatura europea, tiene por objetivo principal explorar las modalidades de la tragedia a partir de las innovaciones introducidas en el género por el Manco de Lepanto. Al enfrentarse a una de las formas dramáticas más reverenciadas por eruditos, teóricos y académicos, podría pensarse que se trata de un acercamiento por completo canónico a la producción cervantina tradicionalmente más desestimada. Sin embargo, como el título de la obra indica, en realidad es una aproximación que reta a las imposiciones ideológicas más rancias de la crítica literaria y de los más asiduos partidarios del canon, para proponer, tomando el marco hispánico áureo como punto de partida, una profunda exploración hacia otros territorios y otras épocas, en busca de la impronta cervantina, que sutilmente se manifiesta como un innovador carácter universalizante e intemporal.

Dos son los conceptos, históricamente relacionados de manera indefectible y estrecha, que con notoriedad estructuran el discurso y las metas del estudio: libertad y heterodoxia. La primera es una constante en la obra de Cervantes; patente de forma plena en el Quijote, es también un elemento que subyace en sus entremeses y, sin lugar a dudas, en la Numancia, pieza que se convierte aquí en el referente primordial para comprender los puntos esenciales en que se centran las innovaciones en el género trágico, en flagrante oposición a las opiniones que con frecuencia han aducido una vuelta a la preceptiva clásica cuando tratan de la composición de esta obra. La heterodoxia, por otro lado, constituye el elemento más provocativo de este volumen, ya que busca derribar las manipulaciones teórico-discursivas con las que 
buena cantidad de críticos y académicos han defendido determinadas ideologías, sin prestar atención a la esencia poética, ajena, según Maestro, a los sistemas sociorreligiosos y filosófico-morales que han usurpado el lugar correspondiente a la libre hermenéutica, es decir, el fenómeno interpretativo que se actualiza sin cánones que manipulen el entendimiento del lector ni teorías que se orienten hacia una determinada moralidad, social o religiosa, en lugar de encaminarse a la genuina apropiación de la obra por medio de la lectura.

De esta forma, el trabajo de Maestro, que a la vez provoca y vindica, aparta la mirada del esplendor por antonomasia de la producción literaria cervantina, para centrarse en aquellas piezas cuya beldad, como la de Calipso, se vio opacada por las preocupaciones de carácter legendario, épico, que anegaban la mente y los deseos de aquellos a quienes pretendieron enamorar. A lo largo de diez capítulos se hace patente la reflexión que busca devolver el protagonismo y la supremacía al ámbito poético; se demuestra, por medio del análisis de los elementos más significativos de determinadas obras, la importancia de la heterodoxia en las innovaciones propuestas por Cervantes, y recogidas de manera particular por autores como Shakespeare, Milton, Alfieri o Büchner. En este sentido, el primer capítulo se destina a exponer el planteamiento esencial que motiva el trabajo; se establecen las herramientas teóricas (los postulados del materialismo filosófico, para mayor especificidad) con que se llevará a cabo la reflexión y exploración de las obras. En este primer capítulo, asimismo, Maestro hace una exhaustiva revisión de los académicos que han tratado la modernidad de Cervantes, cuyo teatro rompe con el modelo clásico pero al mismo tiempo refleja una notoria deuda con la cultura grecolatina, cuya influencia no desaparece ni siquiera en las innovaciones. También se expone al primer grupo de autores en cuya producción se ha de reconocer un dejo de modernidad que comulga con el de la obra cervantina, de manera que Dante, Shakespeare y Molière aportan los primeros puntos de referencia sobre los cuales plantear la búsqueda de rasgos estructurales comunes y que indican una evolución compositiva.

El segundo capítulo se centra en las características de las fallidas experimentaciones trágicas de los contemporáneos de Cervantes, en especial, sobre Lupercio Leonardo de Argensola, en quien la crítica ha querido ver ocasionalmente a un peregrino ídolo para el autor del Quijote, mientras que otros lo han señalado como una figura referencial de que se valió Cervantes para oponerse, desde la narrativa, a Lope y su teatro. A continuación, se analizan las innovadoras características del teatro cervantino, creación por completo extemporánea y heterodoxa que no puede reducirse a los cánones clásicos ni a la usanza atinadamente desarrollada por Lope y continuada por Calderón pero, en opinión de Maestro, incapaz de sobrevivir más allá del período áureo. Es de especial atracción, puesto que constituye uno de los grandes elementos estructurales de la tragedia moderna, la ruptura con la esencia religiosa de la tragedia clásica; la secularización, propuesta en la Numancia, se convierte en uno de los pilares principales que han de sostener la creación literaria a partir de este punto. Sobre esta línea marcada eminentemente por la heterodoxia, el tercer capítulo consiste en explorar los elementos que suponen una transgresión del canon clásico y la sustitución de una metafísica trascendental por una historici- 
dad cercana al momento en que se escribe y que deja de lado la intervención divina, para centrarse en la potencialidad por entero humana, en cinco entremeses atribuidos a Cervantes: Los habladores, La cárcel de Sevilla, El hospital de los podridos, Los romances y Los mirones. Muy pertinente parece la nota que abre este capítulo, para no confundir el propósito del mismo, ya que no es la intención desvelar la autoría definitiva de estas piezas, sino reconocer en ellas este carácter extemporáneo y heterodoxo, que se pone de relieve a lo largo del trabajo.

Con el cuarto capítulo el estudio comienza el análisis de los aspectos más sobresalientes de las obras que muestran una peculiar influencia cervantina, o que comparten con las obras del Manco de Lepanto un carácter innovador y heterodoxo. El primer punto de comparación es el empleo de la metateatralidad en la dramaturgia shakesperiana, en la que también es posible reconocer una importante concesión estructural a la voluntad y la razón humanas, ante un orden metafísico trascendental que se esmera en colocar en el plano central a la divinidad. Sin embargo, a diferencia de Shakespeare, Cervantes desmitifica plenamente el elemento numinoso como director de la vida humana, creando una conciencia trágica que surge ante la acción del hombre contra sus semejantes, en lugar de originarse en el actuar homicida de las divinidades justicieras.

En el quinto capítulo se compara la innovación presente en la obra de Milton, Samson Agonistes, con la reconocible en la Numancia. Nuevamente, la desmitificación del orden metafísico se esgrime como el elemento central, producto de la aplastante conciencia que tienen los autores de su realidad en tanto que hombres. Tanto Milton como Cervantes reconocen el valor del sufrimiento de los humildes, la humanidad del vulgo, lo que supone una clara oposición a la tradicional concepción de lo trágico. En este sentido, resalta el conciso análisis de los elementos clásicos que afectan a las obras, pero que en absoluto constituyen el eje estructurador de las mismas.

El capítulo sexto se centra en la obra trágica de Vittorio Alfieri, que funciona de manera poco convencional, a pesar de adaptarse a la tendencia neoclacisista de la época; en el plano formal, es reconocible la esencia de la tragedia clásica, aunque de la misma manera que ocurre con Milton, se trata de una presencia superficial, ya que funcionalmente las obras tienden hacia el melodrama, forma esencialmente burguesa que adquiere mayor protagonismo a medida que las estructuras clásicas van degenerando en otras. Al igual que la obra cervantina, las tragedias de Alfieri se adscriben a la poética de la libertad, y puede decirse que conforman la última muestra trágica que, de una forma u otra, mantiene viva la cohesión formal, cuyo destino es la extinción al ser incapaz de continuar conjugándose con la negación de un orden trascendental y la desmitificación de los personajes heroicos. Sobre esta línea, el capítulo siguiente trata de la tragedia contemporánea, es decir, la definitiva ruptura con el canon antiguo, lo que implica la plena continuidad de las innovaciones iniciadas por Cervantes. Se estudia, entonces, el papel de Büchner como primer tragediógrafo por entero contemporáneo, tanto por su emancipación definitiva de las formas clásicas, como por el papel protagónico que en su obra adquiere la experiencia vital humana en la realización de la tragedia. De la misma 
forma que la Numancia se manifiesta ajena a la trascendencia metafísica y coloca en el centro estructurador a la historicidad, Büchner extrapola este laicismo, como una realización plena de la innovación cervantina, y plantea una tragedia sustentada en las condiciones materiales de la gente humilde y marginal. Es aquí donde las derivaciones de la tragedia clásica alcanzan su expresión suma.

Los últimos tres capítulos, finalmente, exploran las relaciones de Casona, García Lorca y Torrente Ballester con la poética cervantina. El primero, desde su poética de lo imaginario, alcanza un grado de libertad y laicismo irreductible a lo que, en ocasiones, se ha tildado de evasión y escapismo; en consonancia con la astuta crítica que se reconoce en diversos pasajes de la obra de Cervantes, la poética de Casona desemboca en una iluminada censura sobre los aspectos negativos de la sociedad, sin embargo su mayor acierto es la íntima apropiación del sentimiento de libertad, tan potente y constante en el Quijote, que termina por convertirse en una exaltación de la capacidad humana para actuar por cuenta propia.

Al tratar sobre la obra de Lorca, Maestro recuerda el prolijo uso del simbolismo y la presencia de personajes que encarnan impulsos psicológicos esenciales, lo que otorga una funcionalidad poética al deseo y, además constituye una característica propia del modernismo. Sobre la misma línea, amor y muerte se encuentran pasmosamente próximos en la obra del granadino, hecho que exalta el goce y el placer ante la irrefrenable fugacidad de la vida. En este marco, el teatro lorquiano se nutre del cervantino únicamente para adquirir modelos efectivos en las situaciones que pretende recrear y contra las que protesta desde la perspectiva social; sin embargo, es evidente la ausencia de la agudeza crítica que caracteriza a Cervantes, éste ofrece soluciones y presenta personajes conscientes del papel de la voluntad y la razón en la confección del propio destino, Lorca por su parte presenta víctimas incapaces de resolver la problemática a la que se enfrentan, su intención es expresar la queja llana mas no otorgar resolución alguna.

Por último, la obra dramática de Torrente Ballester parece ligada a la de Cervantes incluso desde su génesis, pues Maestro recuerda su queja en el prólogo al lector de las Ocho comedias, queja que parece repetirse, si bien con otras palabras, cuando Torrente reflexiona sobre su papel de dramaturgo, en el que recibió escasa atención, lamentablemente. El análisis final, eminentemente fundamentado sobre Lope de Aguirre, en efecto ofrece una concienzuda revisión de los caracteres cervantinos que se han estudiado a lo largo del volumen. Resulta obvio que la tradición poética que nutre la obra de Torrente no está enfrascada en el marco del Siglo de Oro, sino que precisamente se extiende a los territorios y épocas que este libro ha recorrido en busca de la impronta cervantina. La ligazón y deuda con Cervantes es innegable, pero también está presente la influencia de otros autores. Los dos grandes conceptos estructuradores de la poética cervantina, libertad y heterodoxia, se condensan en la obra de Torrente dentro del ámbito de la plena desmitificación de prototipos humanos vigentes en el siglo pasado, así como en la crítica de las instituciones política y religiosa, y la madurez en el empleo del «personaje nihilista». 
El alcance real del análisis postrero, y en verdad de todo el trabajo, excede con creces a la presente reseña, por lo que, para concluir, sea suficiente reconocer que se trata de un erudito texto, de ágil lectura y provechosas reflexiones, sin duda un encomiable documento que conformará dentro de bien poco una referencia obligada para los entusiastas del teatro cervantino. 
